\title{
Nanomaterial Lipid-Based Carrier for Non-Invasive Capsaicin Delivery; Manufacturing Scale-Up and Human Irritation Assessment
}

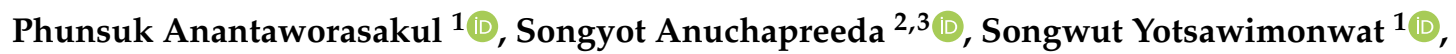 \\ Ornchuma Naksuriya ${ }^{1}$ (D), Suree Lekawanvijit ${ }^{4}$ (D), Napatra Tovanabutra ${ }^{5}$, \\ Pimporn Anantaworasakul 6 (D), Wajee Wattanasri ${ }^{7}$ (D), Narinthorn Buranapreecha ${ }^{77}$ (D) \\ and Chadarat Ampasavate 1,3,*(D)
}

1 Department of Pharmaceutical Sciences, Faculty of Pharmacy, Chiang Mai University, Chiang Mai 50200, Thailand; phunsuk@gmail.com (P.A.); songwut.y@cmu.ac.th (S.Y.); ornchuma.n@cmu.ac.th (O.N.)

2 Division of Clinical Microscopy, Department of Medical Technology, Faculty of Associated Medical Sciences, Chiang Mai University, Chiang Mai 50200, Thailand; songyot.anuch@cmu.ac.th

3 Center for Research and Development of Natural Products for Health, Chiang Mai University, Chiang Mai 50200, Thailand

4 Department of Pathology, Faculty of Medicine, Chiang Mai University, Chiang Mai 50200, Thailand; suree.lek@cmu.ac.th

5 Division of Dermatology, Department of Internal Medicine, Faculty of Medicine, Chiang Mai University, Chiang Mai 50200, Thailand; napatra.to@cmu.ac.th

6 International Research and Academic Service Center, International College of Digital Innovation, Chiang Mai University, Chiang Mai 50200, Thailand; pimporn.a@cmu.ac.th

7 BLC Research Center, Bangkok Lab \& Cosmetic Co., Ltd., Ratchaburi 70000, Thailand; wajee@bangkoklab.co.th (W.W.); narinthorn@bangkoklab.co.th (N.B.)

* Correspondence: chadarat.a@cmu.ac.th

Academic Editor: Rita Cortesi

Received: 24 September 2020; Accepted: 12 November 2020; Published: 27 November 2020

\begin{abstract}
Capsaicin is an active compound in chili peppers (Capsicum chinense) that has been approved for chronic pain treatment. The topical application of high-strength capsaicin has been proven to reduce pain; however, skin irritation is a major drawback. The aim of this study was to investigate an appropriate and scalable technique for preparing nanostructured lipid carriers (NLCs) containing $0.25 \%$ capsaicin from capsicum oleoresin (NLC_C) and to evaluate the irritation of human skin by chili-extract-loaded NLCs incorporated in a gel formulation (Gel NLC_C). High-shear homogenization with high intensity $(10,000 \mathrm{rpm})$ was selected to create uniform nanoparticles with a size range from 106 to $156 \mathrm{~nm}$. Both the NLC_C and Gel NLC_C formulations expressed greater physical and chemical stabilities than the free chili formulation. Release and porcine biopsy studies revealed the sustained drug release and significant permeation of the NLCs through the outer skin layer, distributing in the dermis better than the free compounds. Finally, the alleviation of irritation and the decrease in uncomfortable feelings following the application of the Gel NLC_C formulation were compared to the effects from a chili gel and a commercial product in thirty healthy volunteers. The chili-extract-loaded NLCs were shown to be applicable for the transdermal delivery of capsaicin whilst minimizing skin irritation, the major noncompliance cause of patients.
\end{abstract}

Keywords: capsaicin; chili extract; NLC; topical delivery system; human skin irritation 


\section{Introduction}

The transdermal route is one way of administering active compounds on the skin to overcome limitations such as first pass metabolism or target delivery to a specific skin layer [1]. Lipid-based nanocarriers in the form of nanostructure lipid carriers (NLCs) have gained much attention as an alternative to solid lipid nanoparticles (SLNs) for drug delivery, to overcome the limitations of SLNs such as drug leakage during storage and low drug-loading capacity [2,3]. These carriers are advantageous for several routes of administration: the parenteral, oral, especially topical routes $[4,5]$. For safety reasons, most of the lipids used in the lipid matrices for SLN and NLC fabrication are physiological and biodegradable components with GRAS (generally recognized as safe) status and are frequently used in commercially available topical cosmetic or pharmaceutical preparations $[4,6]$. The small size lipid nanoparticles exhibit an occlusive effect that improves skin hydration and increases drug permeation [7]. Further advantages of their use for administering pharmaceuticals include their ability to control a drug's release, reduce its side effects, and target its delivery [8].

Capsaicinoids, major active compounds in chilis (Capsicum chinense), have been used in folk medicine for their therapeutic effects, including analgesic and anti-inflammatory effects, and inhibition of gastrointestinal, cardiovascular, and respiratory diseases [9]. Capsaicin (8-methyl- $N$-vanillyltrans-6-nonenamide) is an active compound and is used as a marker for chili extracts. The benefits of capsaicin in topical applications for various diseases such as musculoskeletal pain, osteoarthritis, rheumatoid arthritis, diabetic neuropathy, and post-herpetic neuralgia have been proven $[10,11]$. Commercial products are available in the forms of creams, gels, lotions, ointments, or patch formulations-typically containing $0.0125-0.075 \%$ capsaicin by weight—for chronic pain management, with application three to five times daily for a few months [12]. The pharmacological mechanisms of capsaicin in pain control are associated with TRPV1 receptors (transient receptor potential vanilloid subfamily, member 1), expressed on nociceptive fibers in the dermis. However, the important problem with chili extract after its application on the skin is severe irritation when capsaicin binds the TRPV1 receptors presented on the keratinocytes in the epidermis [9]. The unwanted side effects of capsaicin products include a burning sensation, leading to severe skin irritation and poor patient compliance $[9,11]$. The development of lipid nanocarriers has been suggested in order to harness the benefits of capsaicin while avoiding its irritative effects.

Previous studies have reported several techniques for preparing chili-extract-loaded lipid-based nanocarriers such as high-pressure homogenization (HPH) [13-15], high-shear homogenization (HSH) $[13,14,16]$, microemulsion techniques [17-19], emulsification sonication [8,16], solventemulsification evaporation [19,20], and solvent-diffusion methods [21]. In the solvent-emulsification evaporation and solvent-diffusion techniques, hazardous organic solvents such as chloroform and dichloromethane were required for the preparation, as well as the emulsification sonication technique in which metal contamination from a sonicating probe was observed in the products $[22,23]$. These are the limitations of most techniques which were developed for lab-scale production. The potential of high-pressure homogenization and the microemulsion method for manufacturing scale-up has been demonstrated [24,25]. The standard method for NLC fabrication using combination technologies consists of high-shear or high-speed homogenization employed in the pre-emulsion step followed by $\mathrm{HPH}$ or emulsification sonication $[23,25,26]$. However, these techniques have limitations regarding performance, such as long particle-size-reduction times, low production capacity, complexity of operation, and the clean-up process, especially in large-scale or industrial-scale production [27]. To avoid multiple steps in nanoparticle production, the HSH-a technique typically used in the pre-emulsion step — can be developed as a single apparatus for lipid-nanoparticle production by the optimization of factors such as the design and size of the generator, speed rate, processing time, viscosity of the medium, and volume of the sample [28].

The main purpose of this study was to investigate a suitable technique for preparing chili-extract-loaded NLCs containing a high concentration of capsaicin $(0.25 \%)$ from chili oleoresin extract to enhance the transdermal delivery and the sustained release of capsaicin, while reducing skin 
irritation. The physicochemical characteristics of the particles obtained from three scale-up techniques, such as the physical and chemical stabilities, were compared to identify the most optimal technique for industrial-scale production. The developed chili-extract-loaded NLCs were incorporated in a gel formulation containing $0.075 \%$ capsaicin. The irritancy of the final formulae was evaluated in humans.

\section{Results and Discussion}

\subsection{Characterization of NLCs Prepared by Different Methods}

Many previous studies had confirmed the superior entrapment efficiency of NLCs compared to that of SLN [2,29,30]. Chili-extract-loaded NLCs (NLC_Cs) were prepared from a lipid mixture and surfactant as described in the previous study [29]. Besides the chemical composition used in the formulations, the production method is a key factor contributing to the characteristics of the lipid nanoparticles. The widely used SLN or NLC production techniques include, but are not limited to, $\mathrm{HPH}, \mathrm{HSH}$, ultrasonication, microemulsion, and solvent-emulsification-evaporation techniques $[23,26]$. Organic solvents are normally used in the solvent-emulsification-evaporation or solvent-dispersion techniques. The evaporation or disposure of the organic solvents creates complexity for the scaling-up process [22,23]. To limit the complexity of the production and the use of hazardous organic solvents, this study employed the HPH and/or HSH methods for NLC production. Both methods produced small-size particles, smaller than $200 \mathrm{~nm}$. As shown in Figure 1a and Table 1, the combination of two processes (HSH and HPH) produced the smallest particle size, followed by NLC production with the HSH with a high shear intensity for a short period (10 min) and the HSH with a low shear intensity for a longer period $(30 \mathrm{~min})$, respectively. The particle size produced by the $\mathrm{HSH}+\mathrm{HPH}$ method was significantly smaller than that produced by the other methods $(p<0.05)$, and the high shear intensity significantly reduced the particle size compared to that achieved with the low shear intensity $(p<0.05)$. The size reduction mechanism of the high-pressure homogenizer basically consists of a positive-displacement pump attached to a homogenizing valve assembly. The pump forces the melted lipid mixture fluids through the homogenizing valve under pressure. The HPH can operate on a combination of shear stress and cavitation forces [31,32]. The HSH produces a smaller droplet size using a rotor-stator mixer set based on a stationary stator coupled with an inside rotor responsible for the high speeds [31]. In this study, all the methods provided a narrow particle size distribution in the NLC dispersions, with polydispersity indices (PDI) less than 0.3. The PDI values obtained with all the methods were not significantly different $(p>0.05)$ on the day after preparation (Day 0$)$. Their surfaces were negatively charged, with zeta potentials ranging from -20 to $-35 \mathrm{mV}$. The characteristics of NLC dispersion on the initial day (Day 0) in terms of particle size and PDI are shown in Figure 1a, and the zeta potentials are shown in Figure $1 \mathrm{~b}$.

Table 1. Stability study of NLCs prepared by different methods-the combination of high-shear homogenization (HSH) and high-pressure homogenization ( $\mathrm{HPH})$, and high-shear homogenization (HSH) with different shear intensities—following storage at room temperature for 30 days.

\begin{tabular}{cccccc}
\hline Characterization & Formulation & Day & HSH + HPH & $\begin{array}{c}\text { HSH } \\
\text { (High Intensity) }\end{array}$ & $\begin{array}{c}\text { HSH } \\
\text { (Low Intensity) }\end{array}$ \\
& & 0 & $70.70 \pm 3.46$ & $91.84 \pm 3.15$ & $119.89 \pm 3.20$ \\
& \multirow{2}{*}{ NLC_B } & 7 & $83.12 \pm 6.82$ & $110.26 \pm 3.26$ & $127.75 \pm 2.38$ \\
& & 14 & $87.53 \pm 1.55$ & $110.70 \pm 3.46$ & $126.35 \pm 1.64$ \\
& & 30 & $95.30 \pm 4.25$ & $111.75 \pm 4.05$ & $184.30 \pm 2.11 *$ \\
\cline { 3 - 6 } Size (nm) & & 0 & $90.70 \pm 0.66$ & $158.30 \pm 2.39$ & $170.49 \pm 4.45$ \\
& \multirow{2}{*}{ NLC_C } & 7 & $94.81 \pm 3.75$ & $153.74 \pm 3.23$ & $174.43 \pm 9.55$ \\
& & 14 & $98.10 \pm 1.24$ & $155.45 \pm 4.84$ & $178.80 \pm 5.78$ \\
& & 30 & $157.60 \pm 2.60 *$ & $156.30 \pm 6.88$ & $222.80 \pm 2.23 *$ \\
\hline
\end{tabular}


Table 1. Cont

\begin{tabular}{|c|c|c|c|c|c|}
\hline Characterization & Formulation & Day & HSH + HPH & $\begin{array}{c}\text { HSH } \\
\text { (High Intensity) }\end{array}$ & $\begin{array}{c}\text { HSH } \\
\text { (Low Intensity) }\end{array}$ \\
\hline \multirow{8}{*}{ PDI } & \multirow{4}{*}{ NLC_B } & 0 & $0.29 \pm 0.02$ & $0.21 \pm 0.02$ & $0.25 \pm 0.06$ \\
\hline & & 7 & $0.31 \pm 0.02$ & $0.26 \pm 0.05$ & $0.31 \pm 0.13$ \\
\hline & & 14 & $0.30 \pm 0.05$ & $0.25 \pm 0.01$ & $0.29 \pm 0.05$ \\
\hline & & 30 & $0.38 \pm 0.03$ & $0.26 \pm 0.02$ & $0.58 \pm 0.06^{*}$ \\
\hline & \multirow{4}{*}{ NLC_C } & 0 & $0.29 \pm 0.03$ & $0.25 \pm 0.01$ & $0.35 \pm 0.01$ \\
\hline & & 7 & $0.30 \pm 0.10$ & $0.26 \pm 0.02$ & $0.39 \pm 0.01$ \\
\hline & & 14 & $0.31 \pm 0.04$ & $0.24 \pm 0.02$ & $0.36 \pm 0.03$ \\
\hline & & 30 & $0.61 \pm 0.03 *$ & $0.28 \pm 0.01$ & $0.54 \pm 0.03 *$ \\
\hline \multirow{8}{*}{$\mathrm{ZP}(\mathrm{mV})$} & \multirow{4}{*}{ NLC_B } & 0 & $-19.88 \pm 1.41$ & $-30.22 \pm 1.02$ & $-29.20 \pm 0.61$ \\
\hline & & 7 & $-16.08 \pm 1.83$ & $-31.30 \pm 4.36$ & $-27.20 \pm 0.61$ \\
\hline & & 14 & $-19.00 \pm 0.66$ & $-25.38 \pm 0.83$ & $-26.20 \pm 0.72$ \\
\hline & & 30 & $-18.78 \pm 0.56$ & $-29.39 \pm 2.75$ & $-14.35 \pm 1.45$ * \\
\hline & \multirow{4}{*}{ NLC_C } & 0 & $-24.97 \pm 0.91$ & $-33.74 \pm 0.71$ & $-32.76 \pm 0.60$ \\
\hline & & 7 & $-27.64 \pm 1.11$ & $-38.10 \pm 0.43$ & $-30.76 \pm 0.70$ \\
\hline & & 14 & $-26.29 \pm 0.48$ & $-35.66 \pm 0.98$ & $-24.55 \pm 0.53$ \\
\hline & & 30 & $-17.29 \pm 0.44 *$ & $-39.27 \pm 0.28$ & $-14.33 \pm 0.74$ * \\
\hline
\end{tabular}

Abbreviations: PDI, polydispersity index; ZP, zeta potential; NLC_B, blank nanostructured lipid carriers; NLC_C, chili-extract-loaded nanostructured lipid carriers. ${ }^{*}$ The values are significantly different $(p<0.05)$ compared to initial formulation (Day 0).

(a)

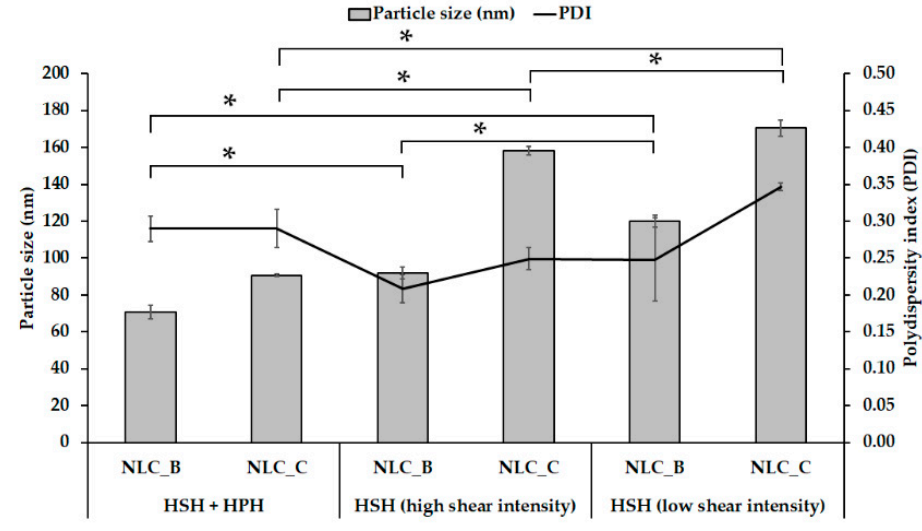

(b)

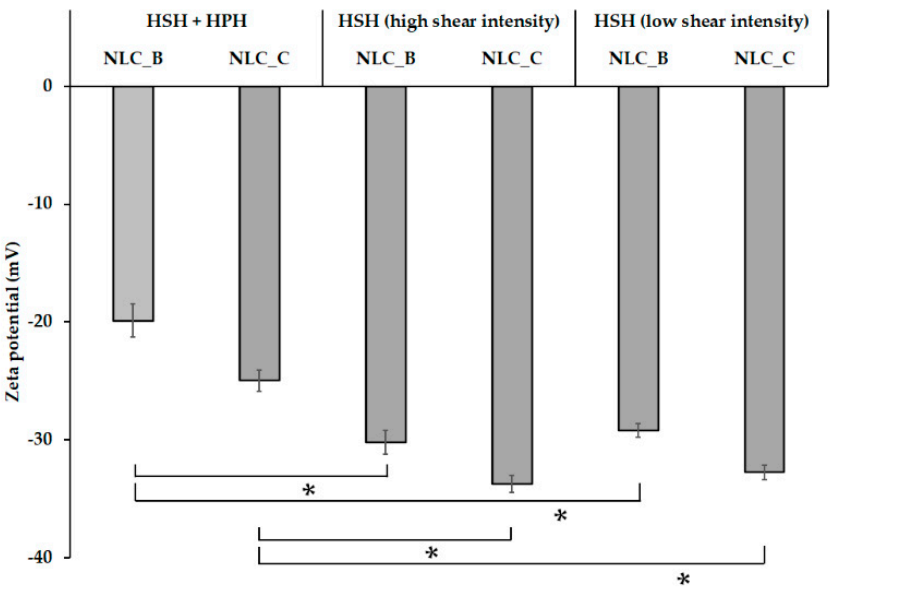

Figure 1. Influence of techniques for nanostructured lipid carriers (NLC) fabrication on (a) the particle size and size distribution (PDI) and (b) zeta potential. The techniques included (1) a combination of high-shear homogenization (HSH) and high-pressure homogenization (HPH), (2) HSH with a high shear intensity, and (3) HSH with a low shear intensity. Abbreviations: NLC_B, blank NLC; NLC_C, chili-extract-loaded NLC. ${ }^{*}$ The particle size and zeta potential values are significantly different $(p<0.05)$ between the methods. 


\subsection{NLC Stability}

The stability of the NLCs, blank NLCs (NLC_Bs), and chili-extract-loaded NLCs (NLC_Cs) produced by the different methods were observed after storage in closed containers at room temperature for 30 days. The particle size of the NLC_Cs significantly increased after 14 days of storage, except for those produced by HSH with a high shear intensity. Table 1 shows the stability trends of the NLCs produced by the different techniques after a month of storage, in terms of the particle size, size distribution, and surface charge. These stability results show the potential of HSH operated at high intensity for preparing NLC_C dispersions. Although HPH is the most commonly used technique for lipid-based nanoparticle fabrication because it can form small particle sizes, it results in coalescence and agglomeration upon storage due to the particles that were separated by the powerful HPH re-combining after the dissipation of the high kinetic energy [26,33]. In addition, the high temperature and shear stress from the process could induce gel formation by increasing the kinetic energy of the particles and their collision; instability of the nanoparticles upon crystallization was induced by a gelling phenomenon [32]. Stability could be achieved by adding sufficient surfactants; however, these are directly related to irritation [32,34]. The factors influencing the stability and size of the particles produced by the HSH method depended on the shear forces and turbulent flow, which produced less energy than those in the HPH method [35]. The HSH is a technique normally used for the coarse-emulsion production (the pre-emulsion step) of lipid-based nanoparticle preparations in the laboratory, pilot, and industrial scales. This technique is easy to handle, cost-effective and less time-consuming, providing nanometric particle sizes along with good formulation development [36,37]. Furthermore, the high-shear homogenizer is a versatile piece of equipment that is widely used as a mixer for preparing various pharmaceutical dosage forms, such as emulsions, creams, lotions, and gels [38]. The parameters influencing the particle size were not only the formulation methods but also the conditions (such as the time and force) in the process, shear intensity, and shear time in the HSH, as well as the pressure and number of homogenization cycles in the HPH. The size distribution and zeta potential are also key factors in the prediction and evaluation of the stability of colloid dispersions. The size distribution affects the physical stability and uniformity of NLCs according to the polydispersity index (PDI) value. The PDI value should be as low as possible for long-term stability. PDI values of $0.1-0.25$ show a narrow size distribution, while those greater than 0.5 imply a broad distribution [39]. The PDI values of the NLCs prepared by all three techniques were approximately $0.25-0.3$ on the first day after preparation, while by the thirtieth day of storage, the combination technique (HSH + HPH) and $\mathrm{HSH}$ with a low shear intensity showed PDI values above 0.5 , which could be related to particle growth or flocculation. Apart from the particle size, a zeta potential (ZP) above $\pm 30 \mathrm{mV}$ was only observed from the production with the high shear HSH technique, representing good electrostatic stabilization, where the attractive forces were lower than the repulsion forces [40]. Thus, for a combination of electrostatic and steric stabilization, an absolute zeta potential value of about $\pm 20 \mathrm{mV}$ is advised [39]. In this study, the zeta potential values of all the formulations were between -20 and $-40 \mathrm{mV}$. After thirty days of storage, only the zeta potential of the NLC dispersion from the HSH with high shear intensity showed an absolute value higher than $\pm 20 \mathrm{mV}$, which is connected with the good stability of the colloidal system. As shown in Table 1, the stability of the NLCs produced from the high shear intensity HSH was higher than that of those from the HSH-followed-by-HPH and low-shear-intensity-HSH techniques. Other techniques, such as melt-dispersion ultrasonication, film ultrasound, and solvent diffusion, were reported to produce broad distributions of particle sizes, with formulations of low predicted physical stability. In addition, their complex processes created some difficulties for NLC large-scale production [41]. A widely used and well-established method for NLC production is high-pressure homogenization (HPH); however, an NLC formulation produced by HSH with a high shear intensity is possible [25,42,43].

According to the particle sizes of the NLCs produced by the different methods, the NLC_Cs produced using $\mathrm{HSH}$ with high shear intensity were chosen for the scale-up NLC preparation. A stability study at different temperatures $-4{ }^{\circ} \mathrm{C}$, room temperature (RT) and $45{ }^{\circ} \mathrm{C}-$ for 90 days was performed. The physical stability of NLC_C showed no significant difference in terms of the particle size, size distribution, zeta potential, and physical characteristics-i.e., phase separation-under $4{ }^{\circ} \mathrm{C}$ 
and RT storage conditions for 90 days, whereas high-temperature $\left(45^{\circ} \mathrm{C}\right)$ storage induced a significant difference in particle size from that at Day 0; the characteristic data are shown in Table 2. Moreover, an enhancement of chemical stability after incorporation into lipid-based nanocarriers was proven in terms of the remaining capsaicin content [42]. In this study, the NLC_C dispersion was stable and more effectively stabilized the capsaicin than the chili-extract solution. The remaining capsaicin contents in the NLC_Cs showed significant differences at 90 days after both RT and $45{ }^{\circ} \mathrm{C}$ storage. Therefore, storage at $4{ }^{\circ} \mathrm{C}$ preserved the particle size and capsaicin content in the NLC up to 90 days. The remaining capsaicin in the chili solution and NLC_Cs is shown in Figure 2a,b, respectively.

Table 2. Stability study of NLC_C formulation produced by HSH (high shear intensity for short time), following storage at different conditions for 90 days.

\begin{tabular}{ccccc}
\hline Day & Characterization & $\mathbf{4}^{\circ} \mathbf{C}$ & Room Temperature & $\mathbf{4 5}^{\circ} \mathbf{C}$ \\
\hline \multirow{4}{*}{0} & Size $(\mathrm{nm})$ & & $180.20 \pm 1.33$ & \\
& PDI & & $0.22 \pm 0.02$ & \\
& ZP (mV) & & $-35.84 \pm 0.78$ & \\
\multirow{3}{*}{30} & Size $(\mathrm{nm})$ & $187.22 \pm 9.65$ & $181.20 \pm 5.27$ & $155.32 \pm 2.27^{*}$ \\
& PDI & $0.31 \pm 0.03$ & $0.25 \pm 0.03$ & $0.22 \pm 0.02$ \\
& ZP (mV) & $-34.72 \pm 1.53$ & $-34.46 \pm 0.78$ & $-34.16 \pm 1.11$ \\
\hline \multirow{4}{*}{60} & Size (nm) & $198.30 \pm 24.43$ & $179.60 \pm 3.55$ & $160.84 \pm 5.62^{*}$ \\
& PDI & $0.39 \pm 0.08$ & $0.29 \pm 0.04$ & $0.26 \pm 0.04$ \\
& ZP (mV) & $-40.16 \pm 0.44$ & $-41.34 \pm 0.39$ & $-45.74 \pm 1.72$ \\
\hline \multirow{4}{*}{90} & Size (nm) & $196.58 \pm 17.46$ & $180.72 \pm 5.36$ & $205.98 \pm 3.10^{*}$ \\
& PDI & $0.49 \pm 0.05$ & $0.30 \pm 0.04$ & $0.30 \pm 0.02$ \\
& ZP (mV) & $-41.50 \pm 1.93$ & $-45.56 \pm 1.52$ & $-43.34 \pm 1.24$ \\
\hline
\end{tabular}

Abbreviations: PDI, polydispersity index; ZP, zeta potential. ${ }^{*}$ The values are significantly different $(p<0.05)$ compared to those for the initial formulation (Day 0 ).

$\square$ Day $0 \quad \square$ Day $30 \quad \square$ Day $60 \quad \square$ Day 90

(a)

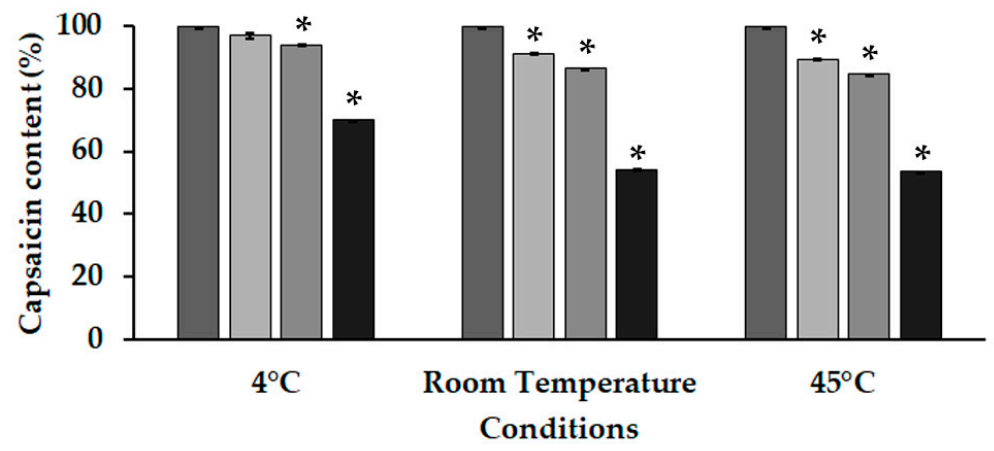

(b)

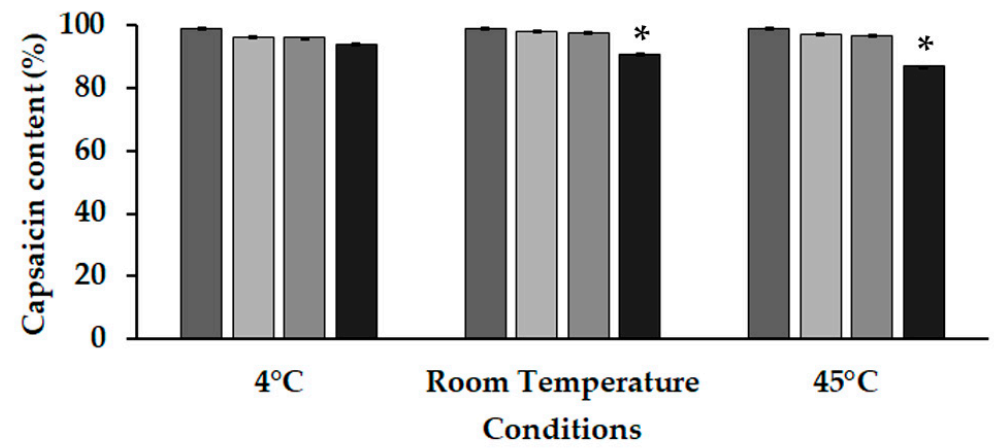

Figure 2. Percentages of capsaicin contents following 90 day storage of (a) chili-extract solution and (b) NLC_C, prepared by HSH with high shear intensity, at different conditions: $4{ }^{\circ} \mathrm{C}$, room temperature (RT), and $45{ }^{\circ} \mathrm{C} .{ }^{*}$ The values are significantly different $(p<0.05)$ compared to those for the initial formulation (Day 0). 


\subsection{TEM Analysis}

The NLCs prepared by HSH with high shear intensity were almost spherical and uniform in shape, with smooth surfaces. The particle diameters were approximately distributed between 100 and $200 \mathrm{~nm}$. The chili-extract-loaded nanoparticles (NLC_C) were larger than the blank nanoparticles (NLC_B), implying the successful entrapment of the chili extract in the lipid-based nanoparticles. The morphologies of the NLC_Bs and NLC_Cs are shown in Figure 3a,b, respectively.

(a)

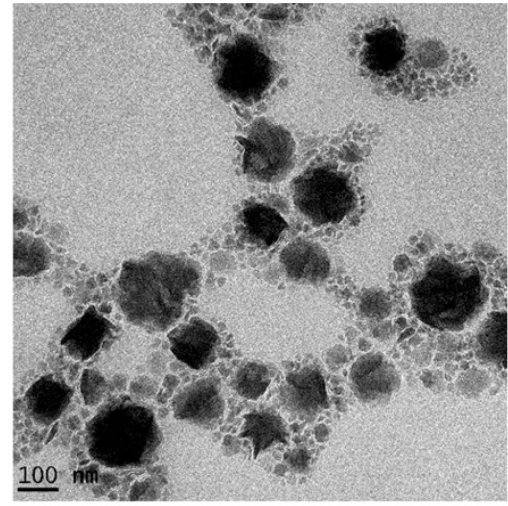

(b)

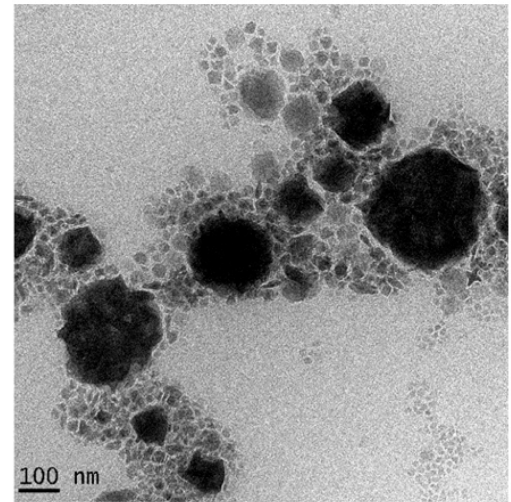

Figure 3. Transmission electron microscopy (TEM) images of nanostructured lipid carriers (NLC) prepared by high-shear homogenization (HSH) with high shear intensity; (a) blank NLC and (b) chili-extract-loaded NLC.

\subsection{HPLC Method Validation}

According to the International Conference on Harmonization of Technical Requirements for Registration Pharmaceuticals for Human use (ICH) guidelines [44] and Association of Analytical Communities (AOAC) guidelines [45], the HPLC analytical method for capsaicin analysis was validated in terms of specificity, accuracy, precision, linearity, limit of detection (LOD), and limit of quantitation (LOQ).

The overall accuracy and precision of the capsaicin analytical method was found to be consistent with acceptance criteria in the guidelines. Good linearity of calibration curves of capsaicin was observed over the concentration range of $0.25-100 \mu \mathrm{g} / \mathrm{mL}$ by visual inspection and by calculating the correlation coefficient $\left(R^{2}\right.$ of $\left.0.9996 \pm 0.0004\right)$. Specificity of the analytical method is as illustrated from the representative HPLC chromatograms of capsaicin standard, the chili-extract-loaded nanostructured lipid carriers (NLC_Cs), and the gel formulation containing NLC_C (Gel NLC_C) was demonstrated and other details were summarized in a Supplementary Materials.

\subsection{Characterization and Stability Study of Chili-Extract-Loaded NLCs Incorporated in Gel Formulation}

The gel formulations of chili-extract-loaded NLCs and chili extract were stored in closed containers at room temperature for 15 days and under accelerated conditions by heating-cooling for seven cycles. The physical appearance, $\mathrm{pH}$, viscosity, and capsaicin content were observed. The gel formulations were stable; the $\mathrm{pH}$ and viscosity of each formulation were not significantly different from those in the initial formulation (Day 0). The $\mathrm{pH}$ of all the gel formulations was approximately 7.0, which is within the acceptable limits for topical applications, 5.0-8.0 [46]. Moreover, chemical stability is one of the most important aspects in nanoparticle development $[40,47]$. The capsaicin content in the gel formulations after storage under two different conditions demonstrated the efficacy of NLCs in protecting capsaicin from oxidation and degradation during analysis or storage. A comparison of the capsaicin content between the chili-extract-incorporated-in-gel (Gel Chili) and NLC_C-incorporatedin-gel (Gel NLC_C) formulations revealed significant differences in Gel Chili from the initial formulation (Day 0). The stability of the gel formulation in terms of the $\mathrm{pH}$, viscosity, and remaining capsaicin is shown in Figure $4 \mathrm{a}-\mathrm{c}$, respectively. 


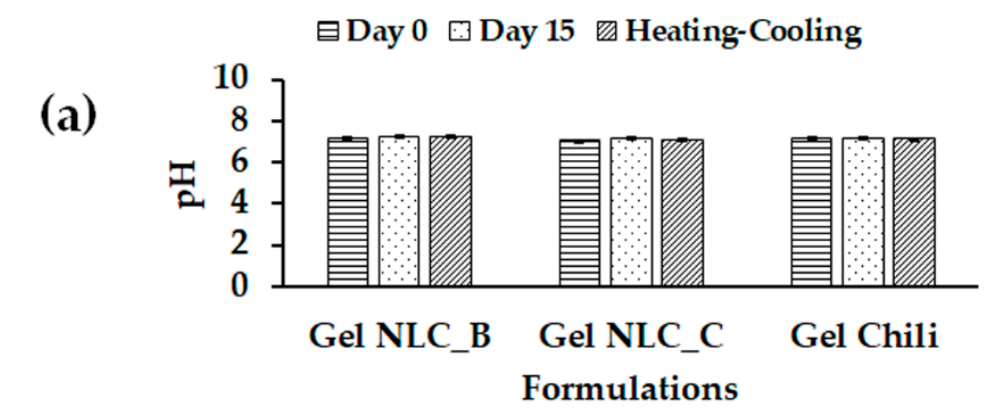

(b)

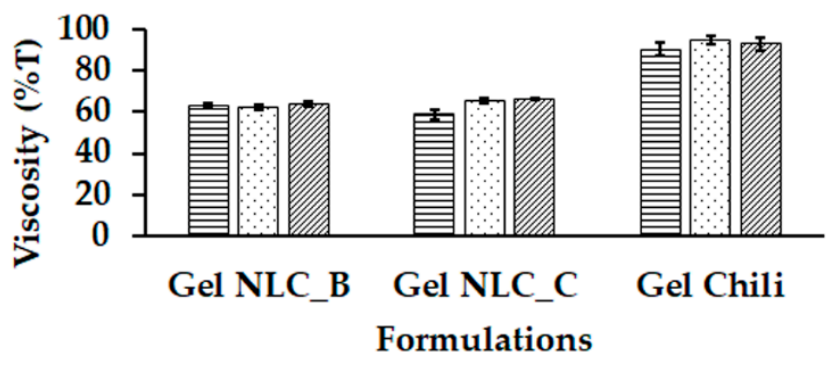

(c)

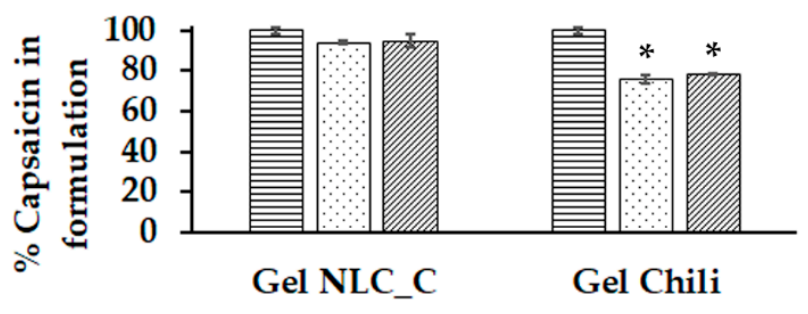

Formulations

Figure 4. Stability study data of gel formulations: (a) $\mathrm{pH}$, (b) viscosity, and (c) remaining capsaicin content in gel formulations after storage at room temperature and accelerated conditions. Abbreviations: NLC, nanostructured lipid carriers; Gel NLC_B, blank NLC-incorporate-in-gel; Gel NLC_C, chili-extract-loaded NLC-incorporate-in-gel; Gel Chili, chili-extract-incorporate-in-gel. * The values are significantly different $(p<0.05)$ compared to those for the initial formulation (Day 0).

\subsection{In Vitro Release Study}

The SnakeSkin ${ }^{\mathrm{TM}}$ dialysis tubing is made from regenerated-cellulose, which is a commercially available membrane with a well-controlled molecular weight (MW) cut-off. The SnakeSkin ${ }^{\mathrm{TM}}$ is widely used as a membrane model for an in vitro release study similar to a regular dialysis tube [48]. The release of NLC_Cs and Gel NLC_Cs was studied in vitro over $24 \mathrm{~h}$ using the dialysis method with PBS (pH 7.4)/ethanol (1:1) as the medium and compared with that of the chili extract solution and Gel Chili. Ethanol was added in the medium for increasing the solubility of capsaicin to reach the sink condition [49,50]. The release profiles of the NLC_C dispersion and Gel NLC_C showed a sustained release, which is attributable to the fact that capsaicin is a lipophilic compound. Thus, the capsaicin in chili prefers to stay within the lipid phase of NLCs rather than being released into an aqueous medium [51]. The release of capsaicin was slower from the gel formulation due to the release-retarding effect of the gelling agent's polymeric matrix [5]. The sustained release may limit the side effects of the capsaicin [47]. The released profile was quantitatively determined using an HPLC system. The percentages of capsaicin release from NLC_C and Gel NLC_C are shown in Figure 5a,b, respectively. Moreover, Table 3 exhibits the correlation coefficient $\left(R^{2}\right)$ values of the kinetic release of capsaicin from different formulations. The release kinetics of capsaicin from NLC_C, Gel Chili, and Gel NLC_C were best fitted into the zero-order model. The zero-order kinetic model is related to various drug delivery systems, such as transdermal systems, slow release matrix tablets in coated forms, and osmotic systems [52]. The zero-order kinetic model is suitable for prolonged drug release because drug efficacy can be increased while dose frequency and toxicity can be reduced [53]. 
(a)

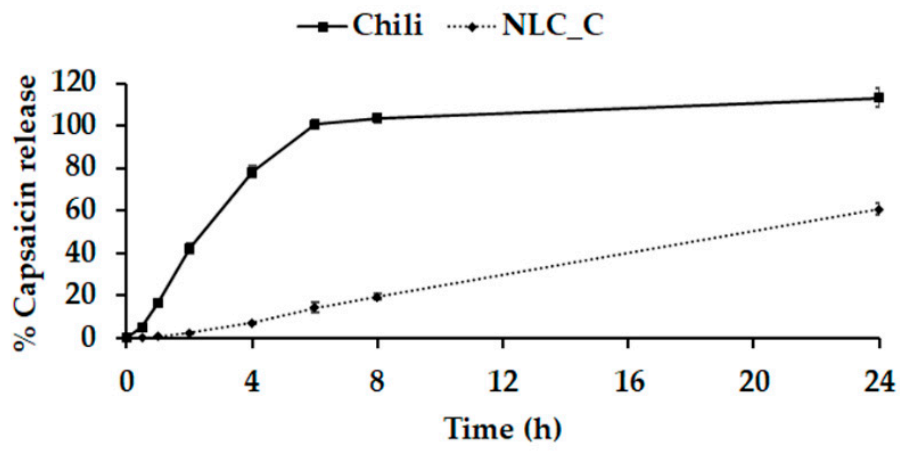

(b)

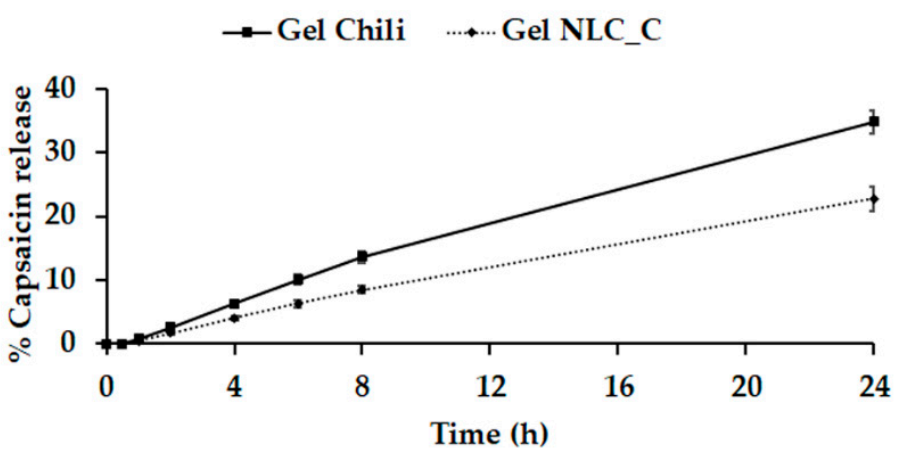

Figure 5. In vitro release study of (a) aqueous dispersions—chili extract and NLC_C_-and (b) gel formulations; Gel Chili and Gel NLC_C, at various time points within 24 h. Abbreviations: NLC_C, chili-extract-loaded-nanostructured lipid carriers; Gel Chili, chili-extract-incorporate-in-gel; Gel NLC_C, chili-extract-loaded NLC-incorporate-in-gel.

Table 3. Correlation coefficient $\left(\mathrm{R}^{2}\right)$ values of the capsaicin-release kinetic models.

\begin{tabular}{cccc}
\hline Formulation & Zero-Order & First-Order & Higuchi \\
\hline Chili extract & 0.5883 & 0.3872 & 0.8007 \\
NLC_C & 0.9988 & 0.5554 & 0.9334 \\
Gel Chili & 0.9940 & 0.6829 & 0.9714 \\
Gel NLC_C & 0.9957 & 0.6656 & 0.9694 \\
\hline
\end{tabular}

Abbreviations: NLC_C, chili-extract-loaded-nanostructured lipid carriers; Gel Chili, chili-extract-incorporate-in-gel; Gel NLC_C, chili-extract-loaded NLC-incorporate-in-gel.

\subsection{Study of NLC Distribution through the Skin Layers Using Fluorescence Microscopy}

Penetration images were obtained using various techniques such as optical microscopy, fluorescence microscopy, confocal laser scanning microscopy (CLSM), and Raman spectroscopy. Fluorescence microscopy is useful in cell physiology study, especially for studying skin delivery such as in permeation studies [54-56]. The porcine skin is a membrane barrier which can be defined by the skin layers like the human skin, enabling us to observe the fluorescent dye distribution and permeation in different layers [57]. Fluorescein is a hydrophobic fluorescent dye used as a marker for skin permeation studies. PBS ( $\mathrm{pH} 7.4)$ was used as a negative control, and fluorescein solution $(0.1 \%(w / v))$ was used as a positive control. The ability of NLCs containing $0.1 \%(w / v)$ fluorescein (NLC_F) to permeate through porcine skin samples was studied for $24 \mathrm{~h}$. The porcine skin samples were cut into vertically cross-sectional slices, and a fluorescent microscope was used to visualize the permeation profile through the skin layers in the fluorescein isothiocyanate (FITC) channel. A fluorescent image of the PBS-treated skin sample showed the skin auto-fluorescence. The image of the fluorescein solution $(0.1 \% w / v)$ showed that most of the fluorescent dye permeated and accumulated in the stratum corneum layer. Moreover, the image of the nanodelivery system containing $0.1 \%(w / v)$ fluorescein showed that the fluorescent dye permeated deeply through the stratum corneum layer and was distributed in the 
dermis layer. The effective lipid-based nanoparticles were able to deliver the hydrophobic compound to the skin sample due to the occlusive effect, with the enhanced penetration of molecules through the stratum corneum, similar to observations from previous studies [36,58]. A phase contrast image of the same skin sample was observed under a regular microscope (under bright field) as shown in Figure 6a, and fluorescent images are shown in Figure $6 \mathrm{~b}-\mathrm{d}$.

(a)

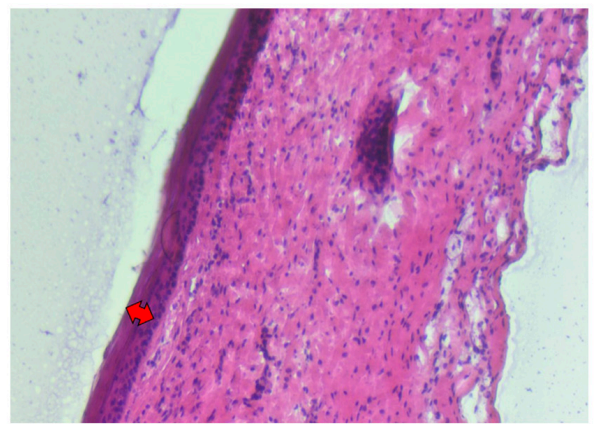

(c)

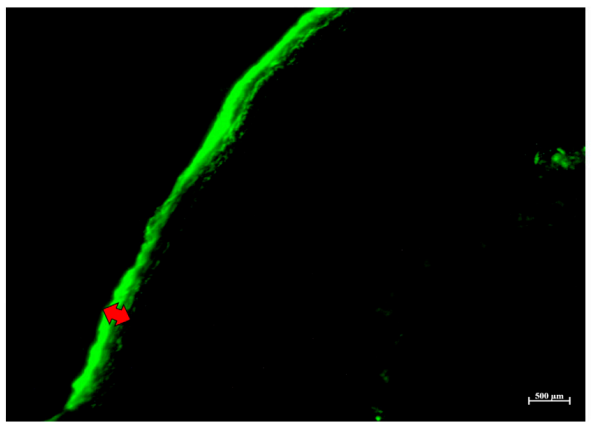

(b)

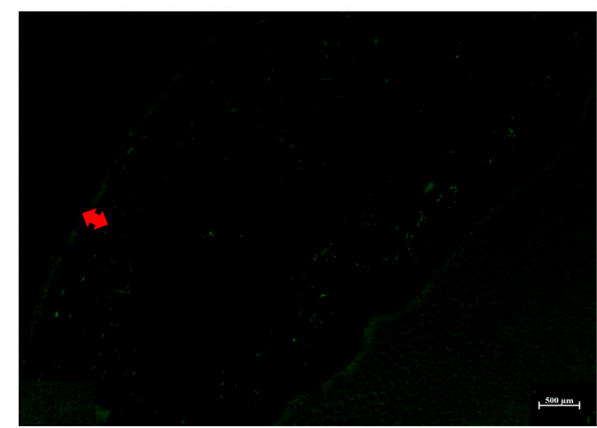

(d)

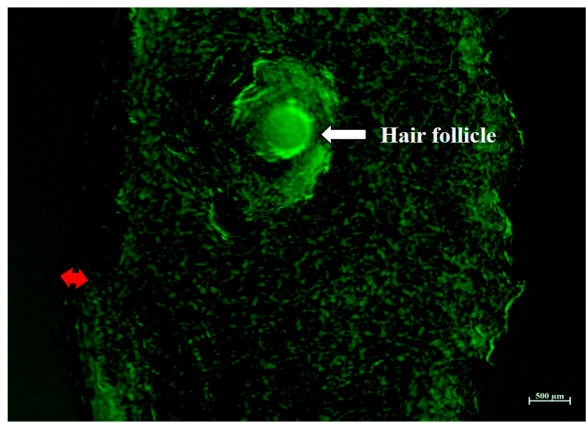

Figure 6. Fluorescence images of fluorescein distribution through the porcine skin samples; (a) a phase contrast image of the skin sample observed under a regular microscope; fluorescent images of the porcine skin sample treated with (b) PBS, pH 7.4; (c) fluorescein solution at $0.1 \%(w / v)$; and (d) NLC_F. Red arrows show the boundary of the epidermis layer. Abbreviations: NLC_F, fluorescein-loaded NLC.

\subsection{In Vivo Human Skin Irritation Test in Volunteers}

Healthy male and female volunteers in the age group of 20-50 years were randomly included in this study. None of the volunteers had skin diseases or distinct signs of extrinsic skin aging in the test areas; however, irritation from capsaicin could occur in all age ranges. In the trial treatment, all sample types were applied to each individual who served as his/her own control. Erythema, a common sign of skin irritation, was evaluated using a Mexameter ${ }^{\circledR}$, visual determination and sensory analysis. An example photograph illustrating irritation on a volunteer's skin at 60 min is shown in Figure 7a. According to visual observation, Gel Chili (F3) and the commercial product (F6) induced more severe erythema than the other formulations. The erythema values measured by the Mexameter ${ }^{\circledR}$ in Figure $7 \mathrm{~b}$ demonstrates similar results. The erythema values from Gel Chili were significantly higher than those from the other formulations at 60,120, and $180 \mathrm{~min}(p<0.05)$, followed by those from the commercial product at 60 and $120 \mathrm{~min}(p<0.05)$. On the contrary, only the erythema value for Gel NLC_C (F1) at $60 \mathrm{~min}$ was significantly higher than that at the initial time point and for the remaining samples $(p<0.05)$, whereas Gel NLC_B (F2) did not cause significant erythema at any time point, indicating the effectiveness of the NLCs in decreasing skin irritation. The graphical sensory data presented in Figure $7 \mathrm{c}-\mathrm{f}$ express the feelings of the volunteers on rating scales-including pain, itching, redness, and burning - after applying the formulations. They correlate well with the erythema values. Gel Chili showed significantly higher ratings for skin irritation symptoms than the other formulations at $60 \mathrm{~min}$ to $2 \mathrm{~h}(p<0.05)$ for pain, at $30 \mathrm{~min}$ to $3 \mathrm{~h}(p<0.05)$ for itching and erythema (or redness), and $60 \mathrm{~min}$ to $3 \mathrm{~h}(p<0.05)$ for burning sensation. Moreover, the ratings of itching, redness, and burning with Gel 
Chili at $24 \mathrm{~h}$ were significantly higher than those from others, except the commercial product. All the results highlight the advantage of lipid-based nanoparticles in reducing skin irritation by capsaicin.

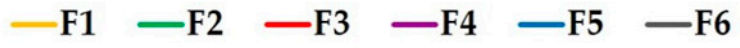

(a)

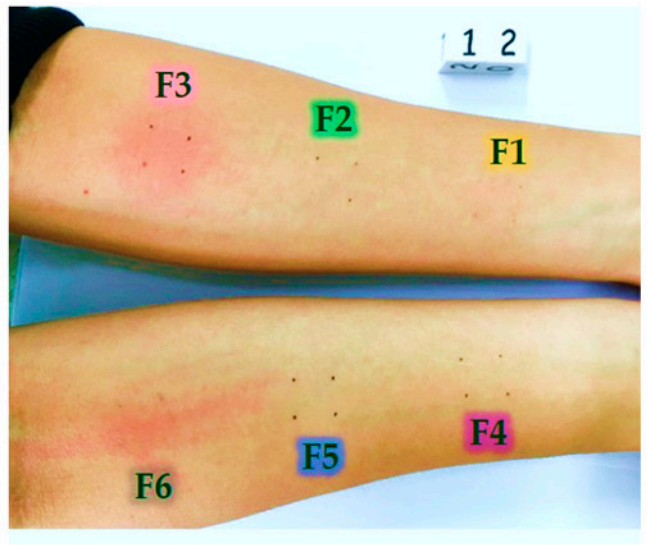

(c)

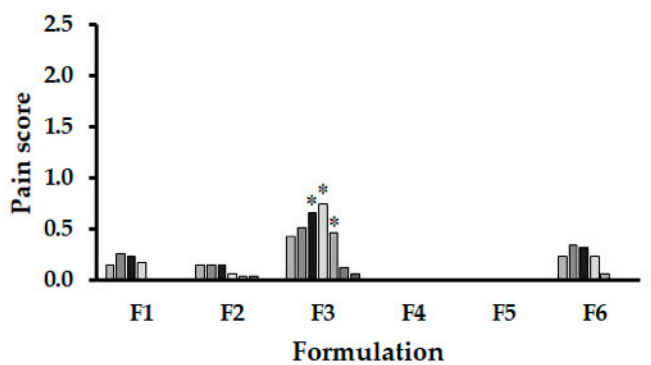

(e)

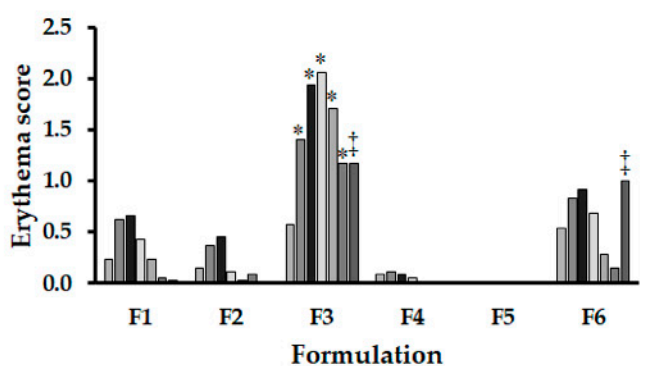

(b)

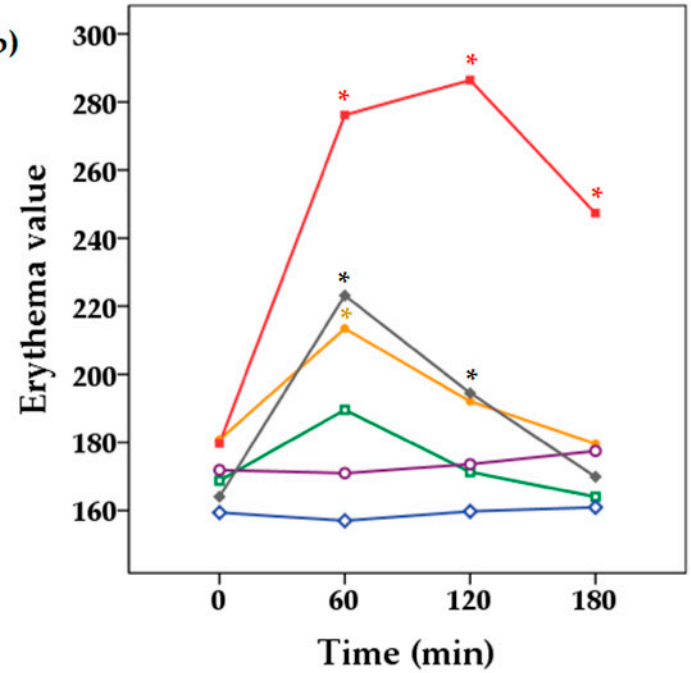

(d)

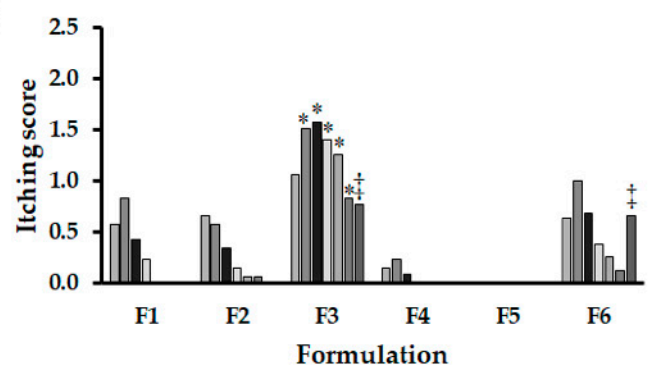

(f)

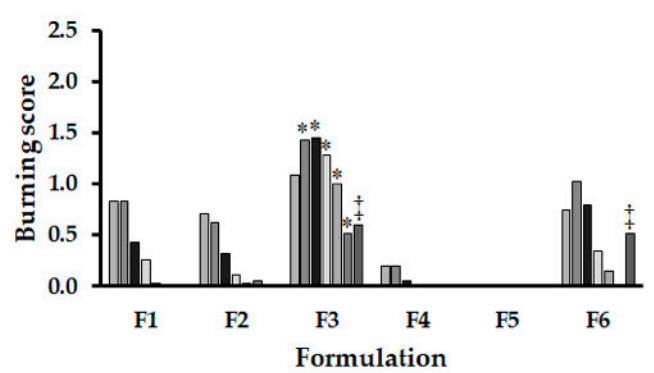

Figure 7. Erythema evaluation after applying each formulation on the human skin for $15 \mathrm{~min}$ and then removing it and leaving it on for 60, 120, and $180 \mathrm{~min}$. (a) An example photo at $60 \mathrm{~min}$; (b) erythema values determined with a Mexameter ${ }^{\circledR}$; pain scores on a sensory scale at $15 \mathrm{~min}, 30 \mathrm{~min}, 60 \mathrm{~min}, 90 \mathrm{~min}$, $2 \mathrm{~h}, 3 \mathrm{~h}$, and $24 \mathrm{~h}$, including for (c) pain, (d) itching, (e) erythema, and (f) burning. * The values are significantly different $(p<0.05)$ from the values for the other formulations, $\ddagger$ The values are significantly different $(p<0.05)$ from the values for the other formulations, except formulations F3 and F6. Note; F1: Gel NLC_C (chili-extract-loaded NLC-incorporated-in-gel formulation); F2: Gel NLC_B (blank NLC-incorporated-in-gel formulation); F3: Gel Chili (chili-extract-incorporated-in-gel formulation); F4: 5\% sodium lauryl sulphate (SLS) solution; F5: Deionized water; F6: Commercial product. 


\section{Materials and Methods}

\subsection{Materials}

A capsaicin standard and a chili extract from Capsicum chinense were obtained from Bangkok Lab and Cosmetic Co., Ltd., Ratchaburi, Thailand. Glyceryl monostearate (GMS), cetyl alcohol (COH), and isopropyl myristate (IPM) were purchased from Namsiang, Bangkok, Thailand. Tween ${ }^{\circledR} 80$ and Span ${ }^{\circledR} 80$ were purchased from NOF Corporation, Tokyo, Japan. All the other chemicals were of the highest grade available. All the solutions were prepared with distilled water.

\subsection{Preparation of Chili-Extract-Loaded Nanostructured-Lipid-Carrier (NLC) Dispersion}

Chili-extract-loaded NLCs (NLC_C) containing $0.25 \%(w / w)$ capsaicin was prepared from lipid mixture and surfactant, consisted of glyceryl monostearate, cetyl alcohol, isopropyl myristate with appropriate HLB non-ionic surfactants. Suitable ratio of the selected liquid lipid, solid lipids surfactant mixtures, and the NLC preparation protocols were modified from the previous study [29]. Briefly, lipid phase and chili extract were melted at $70{ }^{\circ} \mathrm{C}$ under controlled stirring. An aqueous phase was mixed with a non-ionic surfactant and heated to $75^{\circ} \mathrm{C}$. Then, both phases were mixed together to form a pre-emulsion before subjecting to a particle-size-reduction step. Three different methods including (1) the combination of two processes, high-shear homogenization (HSH) followed by high-pressure homogenization (HPH); (2) HSH with a high shear intensity; and (3) HSH with a low shear intensity were performed for NLC preparation. In the first method, a lipid phase was gently added into an aqueous phase and thoroughly mixed using a high-shear homogenizer (Ultra-Turrax ${ }^{\circledR}$ T25, IKA-Werke GmbH \& Company KG, Staufen, Germany) at $5000 \mathrm{rpm}$ for $5 \mathrm{~min}$ before a size-reducing step performed with a high-pressure homogenizer (APV1000, Invensys APV products, Silkeborg, Denmark) at 500 bar for 3 cycles. In the second, the emulsion mixture was mixed by using HSH with a high shear intensity at 10,000 rpm for $10 \mathrm{~min}$, and in the third, HSH was used with a low shear intensity at $5000 \mathrm{rpm}$ for $30 \mathrm{~min}$. After the particle-size reduction step, all samples were left to cool to room temperature. The characteristics of the lipid nanoparticles derived from these three methods were compared to identify the most suitable technique for industrial-scale production.

\subsection{Preparation of Chili-Extract-Loaded NLCs Incorporated in Gel Formulation}

The suitable method of chili-extract-loaded NLC preparation was applied in pilot-scale NLC production. The concentrated capsaicin at $0.25 \%(w / w)$ in the NLC suspension was further incorporated in a gel-based formulation to contain the final $0.075 \%(w / w)$ of capsaicin, a registered strength in the market. Gel-based formulation was a hydrophilic gel consisting of Carbomer and cellulose derivatives. The gel forming polymers were dispersed in distilled water containing propylene glycol $(8 \%(w / w))$. The NLC dispersion and gel-based formulation were mixed in a high-shear homogenizer $500 \mathrm{rpm}$ for up to 10 min until homogeneous.

\subsection{HPLC Analysis}

The precise capsaicin content in each formulation was determined by high-performance liquid chromatography (HPLC), using the HP1100 chromatographic system (Hewlett-Packard, Waldbronn, Germany) with a XBridge C18 (250 × $4.6 \mathrm{~mm}$ i.d., $5 \mu \mathrm{m}$, Waters, MA, USA). The mobile phase was a mixture of acetonitrile and $1 \%$ acetic acid at a ratio of $1: 1(v / v)$, and the flow rate was $1 \mathrm{~mL} / \mathrm{min}$ at room temperature. The injection volume was $10 \mu \mathrm{L}$, and an ultra-violet (UV) detector was set at a wavelength of $280 \mathrm{~nm}$ [29]. The capsaicin analysis was validated in terms of accuracy, precision, and linearity. Capsaicin was quantified based on the calibration curve, which had good linearity in the range of $0.25-100 \mu \mathrm{g} / \mathrm{mL}$. All samples were measured in triplicate. 


\subsection{Characterization of Chili-Extract-Loaded NLC Dispersion}

\subsubsection{Particle-Size, Size-Distribution, and Zeta-Potential Analysis}

The particle size, polydispersity index (PDI), and zeta potential (ZP) of the NLCs were determined using a dynamic light scattering (DLS), Zetasizer ${ }^{\circledR}$ version 5.00 (Malvern Instruments, Worcestershire, UK). Samples were diluted with filtered deionized water (D.I. water) at 1:100 before measurement and kept at $25^{\circ} \mathrm{C}$. The experiments were performed in triplicate, and the results are expressed as the mean \pm standard deviation (SD).

\subsubsection{Determination of Entrapment Efficiency (EE)}

The efficiency of the capsaicin entrapment in the NLC particles was determined by an indirect method. Briefly, chili extract and NLC_C colloidal suspension were placed in Amicon ${ }^{\circledR}$ Ultra centrifugal filters (molecular weight cut-off (MWCO) $100 \mathrm{kDa}$; Merck Millipore) and centrifuged at 5000× $g$ for 15 min at $4{ }^{\circ} \mathrm{C}$ (Sorvall ${ }^{\mathrm{TM}}$ ST 16R, Thermo Fisher Scientific, Langenselbold, Germany). An aliquot of the filtrate part was dissolved in methanol at 1:20 ratio and further filtered to quantify the amount of free capsaicin using HPLC. The EE was calculated using Equation (1).

$$
\% \mathrm{EE}=[(\text { total amount of capsaicin }- \text { free capsaicin }) \times 100] / \text { total amount of capsaicin }
$$

\subsubsection{Transmission Electron Microscopy (TEM) Analysis}

The morphology of the chili-extract-loaded NLCs was determined by transmission electron microscopy (TEM, JEM-2010, JEOL, Tokyo, Japan). A single drop of diluted nanoparticles with D.I. water was dropped onto a copper grid and negatively stained with $1 \%(w / v)$ aqueous phosphotungstic acid solution. The copper grid was dried at room temperature prior to the analysis. The TEM investigation was performed at $100 \mathrm{kV}$.

\subsection{Characterization of Gel Formulation}

The gel formulations were characterized in terms of $\mathrm{pH}$, viscosity, and capsaicin content. The $\mathrm{pH}$ was measured with a pH meter (inoLab ${ }^{\circledR} \mathrm{pH}$ Level 2, WTW GmbH, Weilheim, Germany), after the dilution of the formulation in D.I. water $(1: 10, w / v)$. The viscosity was determined with a rotary viscometer (RVDV-II+PCP, Brookfield Engineering Laboratories, Middleboro, MA, USA) using cone spindle CPE-42 at $25 \pm 1{ }^{\circ} \mathrm{C}$. The capsaicin content in the gel formulations was extracted with diethyl ether ( $1 \mathrm{~h}$ under mixing at room temperature) and was determined by the HPLC-UV method. All experiments were performed in triplicate, and the results are expressed as the mean \pm SD.

\subsection{Stability Study}

All samples of the NLC_C dispersions prepared by the above-mentioned methods were kept in closed containers at room temperature for 30 days and evaluated for their stability. To ensure that the quality of the selected NLC_Cs were prepared by the suitable technique, the NLC_Cs were stored at different temperatures $\left(4^{\circ} \mathrm{C}\right.$, room temperature (RT), and $\left.45^{\circ} \mathrm{C}\right)$ for 90 days, and then, the stability was assessed in the terms of the particle size, uniformity (PDI), ZP, and remaining capsaicin content compared to that in the chili-extract solution. The chili-extract-loaded NLCs incorporated in the gel formulation (Gel NLC_C) and the chili-extract solution incorporated in a gel (Gel Chili) were stored at room temperature for 15 days and also in an accelerated condition (heating-cooling) for seven cycles. The NLC characteristics and the remaining capsaicin content were also evaluated after incorporation into the gel formulations. The remaining capsaicin content in each formulation was analyzed using the HPLC method as described in Section 3.4. 


\subsection{In Vitro Release Study}

The in vitro release behavior of the chili-extract-loaded NLCs and the chili-extract solution was studied using a modified Franz diffusion method [18,29]. An aliquot of freshly prepared colloidal suspension of chili-extract-loaded NLCs and chili-extract solution containing $0.25 \%(w / w)$ capsaicin was investigated through SnakeSkin ${ }^{\mathrm{TM}}$ dialysis tubing (molecular weight cut-off $10 \mathrm{kDa}$; Thermo Fisher Scientific, Abbott Park, IL, USA), which is made from regenerated-cellulose. The SnakeSkin ${ }^{\mathrm{TM}}$ dialysis tubing was soaked in a mixture medium containing phosphate buffer saline (PBS; pH 7.4) and absolute ethanol at a ratio of 1:1 $(v / v)$ for $12 \mathrm{~h}$ before mounting in a Franz diffusion cell. Franz diffusion cells with a diffusion area of $2.00 \pm 0.42 \mathrm{~cm}^{2}$ were used to study in vitro skin permeation. A receptor chamber $(12 \mathrm{~mL})$ was filled with the mixture medium and kept at $32 \pm 2{ }^{\circ} \mathrm{C}$ with gentle stirring at $200 \mathrm{rpm}$. Samples $(0.8 \mathrm{~mL})$ from the receiving medium were drawn and immediately renewed with fresh medium at $0,0.5,1,2,4,6,8$, and $24 \mathrm{~h}$. For the in vitro release study, gel formulations containing $0.075 \%(w / w)$ capsaicin were applied to donor compartments. The capsaicin released in vitro from the NLC dispersion and gel formulations was quantified using an HPLC-UV system at $280 \mathrm{~nm}$ with an $80 \mu \mathrm{L}$ injection volume. The experiments were carried out in triplicate. The release data were analyzed to determine the correlation coefficient $\left(\mathrm{R}^{2}\right)$ and release kinetics of the NLC dispersion and gel formulations using various mathematical models [59]:

a. Zero order model $Q=Q_{0}+k t$;

b. $\quad$ First order model $Q=Q_{0} \times e^{k t}$;

c. Higuchi model $Q=k \times t^{0.5}$;

Where $Q$ is quantity of capsaicin release in time $t, Q_{0}$ is the initial concentration of capsaicin, $k$ is the rate constant. The model which exhibited the highest correlation coefficient $\left(R^{2}\right)$ value for the capsaicin release data was considered as the best fit.

\subsection{Study of NLC Distribution through the Skin Layers Using Fluorescence Microscopy}

In order to evaluate the distribution of the developed NLCs in different skin layers, a fluorescent dye, fluorescein, was entrapped in the NLCs instead of the chili extract. The skin employed in the study was harvested from the dorsal skin of stillborn piglets. The dye distribution profile in the porcine skin was determined using Franz diffusion cells. The receiver medium was a mixture of PBS (pH 7.4) and ethanol $(1: 1, v / v)$. The studied samples $(500 \mu \mathrm{L})$ were the fluorescein-loaded NLC suspension, a fluorescein solution containing $0.1 \%(w / v)$ fluorescein, and PBS (pH 7.4). They were added into separate donor chambers, and incubated at $32 \pm 2{ }^{\circ} \mathrm{C}$ for $24 \mathrm{~h}$; the skin samples were then cleaned to remove excess formulation and rinsed with $30 \mathrm{~mL}$ of D.I. water. Next, the skin samples were blotted with paper towels until dry. The porcine skin samples were frozen in the Tissue-Tek ${ }^{\circledR}$ optimum cutting temperature (O.C.T.) compound with dry ice and sectioned to produce $5 \mu \mathrm{m}$-thick cross-sectional slices at $-21^{\circ} \mathrm{C}$ using a cryostat microtome (Leica CryoStat, CM3050S, Wetzlar, Germany). The permeation profile through the skin layers was visualized in the vertical sections with a fluorescent microscope (Zeiss Fluorescent microscopy with AxioCam 105 Color camera, Göttingen, Germany). Fluorescent images were captured from the slides using a Zeiss fluorescent microscope in the fluorescein isothiocyanate (FITC) channel, and the files were processed using Zen Pro 2.3.

\subsection{In Vivo Human Skin Irritation}

The patch test was performed to evaluate the irritation of skin by the capsaicin formulations. The protocol was approved by Ethical Review Committee, Faculty of Pharmacy, Chiang Mai University (protocol number 13/2017). Thirty healthy volunteers, male and female between the ages of 20 and 50 years old, were enrolled in the study. Three $0.075 \%(w / w)$ capsaicin formulations-chili-extract-loaded NLCs incorporated in gel formulation (Gel NLC_C), chili extract incorporated in gel formulation (Gel Chili), and the commercial formulation along with positive ( $5 \%(w / v)$ sodium lauryl sulphate (SLS) solution) and negative (blank gel-based formulation (Gel NLC_B) and deionized water) controls-were 
applied on and evaluated in the same person across six different areas $(1.5 \times 1.5 \mathrm{~cm})$ on clean forearms. Using a plastic spatula, $50 \mathrm{mg}$ of each samples were applied and left in contact with the skin for $15 \mathrm{~min}$ before thorough removal with wipes. The skin redness (erythema) before the application and after the removal of the remaining products from the skin for 60,120, and $180 \mathrm{~min}$ was evaluated by visual observation and using a Mexameter ${ }^{\circledR}$ (CK Electronic, Cologne, Germany) [10,60]. The volunteers reported the sensory severity of skin irritation on a scale from 0 to 3 (0: no; 1 : slight; 2: moderate; 3: severe) in terms of pain, itching, erythema, and burning [10]. Sensory data were recorded at 15, 30, $60,90,120$, and $180 \mathrm{~min}$ and $24 \mathrm{~h}$ after the removal the formulations from the skin.

\subsection{Statistical analysis}

Data were collected from three independent experiments and are shown as mean \pm SD. Statistical analysis was performed using $t$-tests, ANOVA, and Tukey's multiple comparison test, using SPSS version 19.0 (IBM ${ }^{\circledR}$ SPSS Statistics, Armonk, NY, USA). The statistical significance of differences less than 0.05 ( $p$-values $<0.05$ ) was considered statistically significant.

\section{Conclusions}

The techniques for preparing and scaling up chili-extract-loaded lipid-based nanocarriers can be performed by high-pressure homogenization and high-shear homogenization methods; however, in this study, a modified high-shear-homogenization approach with high shear intensity was proven as the most suitable for NLC production due to its product outcome, simplicity, versatility, and cost effectiveness for industry. Chili-extract-loaded NLCs containing a high capsaicin concentration $(0.25 \%)$ revealed an optimal particle size around $200 \mathrm{~nm}$, narrow size distribution, high entrapment efficiency, and good physicochemical stability. According to in vitro release and permeability studies, the chili-extract-loaded NLC formulation was more effective in terms of sustained release and distribution in the skin than the unloaded formulation. Furthermore, the gel-based formulation with the chili-extract-loaded NLCs was less irritating to human skin than the chili extract not loaded in NLCs and a commercial product. Therefore, the present study shows that chili-extract-loaded NLCs are suitable as a non-invasive drug delivery system for delivering capsaicin through the skin with minimal potential for irritation.

Supplementary Materials: The following are available online, Figure S1: Representative HPLC chromatograms of capsaicin formulations and Table S1: Intraday and interday accuracy and precision results for capsaicin.

Author Contributions: Conceptualization, P.A. (Phunsuk Anantaworasakul), S.A., N.B. and C.A.; data curation, P.A. (Phunsuk Anantaworasakul), W.W. and C.A.; formal analysis, P.A. (Phunsuk Anantaworasakul), S.Y., N.T. and C.A.; funding acquisition, N.B. and C.A.; investigation, P.A. (Phunsuk Anantaworasakul), S.A., S.L., N.T. and C.A.; methodology, S.Y., S.L., N.T., W.W., N.B. and C.A.; project administration, P.A. (Phunsuk Anantaworasakul), and C.A.; resources, S.A., S.L., W.W., N.B. and C.A.; software, P.A. (Phunsuk Anantaworasakul), S.Y., P.A. (Pimporn Anantaworasakul) and C.A.; supervision, S.A. and C.A.; validation, P.A. (Phunsuk Anantaworasakul) and C.A.; visualization, P.A. (Phunsuk Anantaworasakul), S.L., P.A. (Pimporn Anantaworasakul), N.B. and C.A.; writing-original draft preparation, P.A. (Phunsuk Anantaworasakul), S.Y., O.N., P.A. (Pimporn Anantaworasakul) and N.T.; writing-review and editing, P.A. (Phunsuk Anantaworasakul), S.A., S.Y., O.N., P.A. (Pimporn Anantaworasakul), N.B. and C.A. All authors have read and agreed to the published version of the manuscript.

Funding: This work was supported by the Research and Researchers for Industries (RRI), The Thailand Research Fund (TRF) under the Grant number [PHD56I0047] and the Center for Research and Development of Natural Products for Health, Chiang Mai University, Chiang Mai, Thailand.

Acknowledgments: This work was partially supported by the Center for Research and Development of Natural Products for Health, Chiang Mai University, Thailand, the Faculty of Pharmacy and the Faculty of Medicine, Chiang Mai University, Thailand. Moreover, we are thankful to Bangkok Lab and Cosmetic Co., Ltd., Ratchaburi, Thailand, for collaborating and kindly providing part of the partial funding, the capsaicin standard, and the chili extract used in this study.

Conflicts of Interest: Although the chili extract was provided by Bangkok Lab and Cosmetic Co., Ltd., Ratchaburi, Thailand, the experimental research was conducted independently and the company had no influence in the experimental setup or the interpretation of the results. 


\section{References}

1. Alkilani, A.Z.; McCrudden, M.T.; Donnelly, R.F. Transdermal drug delivery: Innovative pharmaceutical developments based on disruption of the barrier properties of the stratum corneum. Pharmaceutics 2015, 7, 438-470. [CrossRef]

2. Müller, R.H.; Radtke, M.; Wissing, S.A. Solid lipid nanoparticles (SLN) and nanostructured lipid carriers (NLC) in cosmetic and dermatological preparations. Adv. Drug Deliv. Rev. 2002, 54, S131-S155. [CrossRef]

3. Abdelbary, G.; Haider, M. In vitro characterization and growth inhibition effect of nanostructured lipid carriers for controlled delivery of methotrexate. Pharm. Dev. Technol. 2013, 18, 1159-1168. [CrossRef]

4. Souto, E.; Wissing, S.; Barbosa, C.; Müller, R.H. Development of a controlled release formulation based on SLN and NLC for topical clotrimazole delivery. Int. J. Pharm. 2004, 278, 71-77. [CrossRef]

5. $\quad$ Bhaskar, K.; Mohan, C.K.; Lingam, M.; Mohan, S.J.; Venkateswarlu, V.; Rao, Y.M.; Bhaskar, K.; Anbu, J.; Ravichandran, V. Development of SLN and NLC enriched hydrogels for transdermal delivery of nitrendipine: In vitro and in vivo characteristics. Drug Dev. Ind. Pharm. 2009, 35, 98-113. [CrossRef]

6. Joshi, M.; Patravale, V. Formulation and evaluation of nanostructured lipid carrier (NLC)-based gel of Valdecoxib. Drug Dev. Ind. Pharm. 2006, 32, 911-918. [CrossRef]

7. Rajinikanth, P.S.; Chellian, J. Development and evaluation of nanostructured lipid carrier-based hydrogel for topical delivery of 5-fluorouracil. Int. J. Nanomed. 2016, 11, 5067-5077. [CrossRef]

8. Sharma, A.; Jindal, M.; Aggarwal, G.; Jain, S. Development of a novel method for fabrication of solid lipid nanoparticles: Using high shear homogenization and ultrasonication. Res. J. Pharm. Biol. Chem. Sci. 2010, 1, 265-274.

9. Anogianaki, A.; Negrev, N.N.; Shaik, Y.B.; Castellani, M.L.; Frydas, S.; Vecchiet, J.; Tete, S.; Salini, V.; Amicis, D.; Lutiis, M.A.; et al. Capsaicin: An irritant anti-inflammatory compound. J. Biol. Regul. Homeost. Agents 2007, 21,1 .

10. Contri, R.V.; Frank, L.A.; Kaiser, M.; Pohlmann, A.R.; Guterres, S.S. The use of nanoencapsulation to decrease human skin irritation caused by capsaicinoids. Int. J. Nanomed. 2014, 9, 951-962. [CrossRef]

11. Reyes-Escogido, M.L.; Gonzalez-Mondragon, E.G.; Vazquez-Tzompantzi, E. Chemical and pharmacological aspects of capsaicin. Molecules 2011, 16, 1253-1270. [CrossRef]

12. Derry, S.; Moore, R.A. Topical capsaicin (low concentration) for chronic neuropathic pain in adults. Cochrane Database Syst. Rev. 2012. [CrossRef]

13. Kim, J.H.; Ko, J.A.; Kim, J.T.; Cha, D.S.; Cho, J.H.; Park, H.J.; Shin, G.H. Preparation of a capsaicin-loaded nanoemulsion for improving skin penetration. J. Agric. Food Chem. 2014, 62, 725-732. [CrossRef]

14. Teeranachaideekul, V.; Chantaburanan, T.; Junyaprasert, V.B. Influence of state and crystallinity of lipid matrix on physicochemical properties and permeation of capsaicin-loaded lipid nanoparticles for topical delivery. J. Drug Deliv. Sci. Technol. 2017, 39, 300-307. [CrossRef]

15. Somagoni, J.; Boakye, C.H.; Godugu, C.; Patel, A.R.; Faria, H.A.; Zucolotto, V.; Singh, M. Nanomiemgel-A novel drug delivery system for topical application-in vitro and in vivo evaluation. PLoS ONE 2014, 9, e115952. [CrossRef]

16. Wang, X.R.; Gao, S.Q.; Niu, X.Q.; Li, L.J.; Ying, X.Y.; Hu, Z.J.; Gao, J.Q. Capsaicin-loaded nanolipoidal carriers for topical application: Design, characterization, and in vitro/in vivo evaluation. Int. J. Nanomed. 2017, 12, 3881-3898. [CrossRef]

17. Tavano, L.; Alfano, P.; Muzzalupo, R.; Cindio, B. Niosomes vs microemulsions: New carriers for topical delivery of capsaicin. Colloids Surf. B 2011, 87, 333-339. [CrossRef]

18. Popescu, M.; Chiutu, L.; Mircioiu, C.; Dima, S. Capsaicin microemulsions: Preparation, characterization and in vitro release study. Farmacia 2014, 62, 58-68.

19. Raza, K.; Shareef, M.A.; Singal, P.; Sharma, G.; Negi, P.; Katare, O.P. Lipid-based capsaicin-loaded nano-colloidal biocompatible topical carriers with enhanced analgesic potential and decreased dermal irritation. J. Liposome Res. 2014, 24, 290-296. [CrossRef]

20. Sarwa, K.K.; Mazumder, B.; Rudrapal, M.; Verma, V.K. Potential of capsaicin-loaded transfersomes in arthritic rats. Drug Deliv. 2015, 22, 638-646. [CrossRef]

21. Agrawal, U.; Gupta, M.; Vyas, S. Capsaicin delivery into the skin with lipidic nanoparticles for the treatment of psoriasis. Artif. Cells Nanomed. Biotechnol. 2015, 43, 33-39. [CrossRef] 
22. Duong, V.A.; Nguyen, T.T.L.; Maeng, H.J. Preparation of Solid Lipid Nanoparticles and Nanostructured Lipid Carriers for Drug Delivery and the Effects of Preparation Parameters of Solvent Injection Method. Molecules 2020, 25, 4781. [CrossRef]

23. Li, Q.; Cai, T.; Huang, Y.; Xia, X.; Cole, S.P.; Cai, Y. A review of the structure, preparation, and application of NLCs, PNPs, and PLNs. Nanomaterials 2017, 7, 122. [CrossRef]

24. Majumdar, A.; Dubey, N.; Malviya, N. Nanostructure lipid carriers: A promising tool for the drug delivery in the treatment of skin cancer. Asian J. Pharm. Clin. Res. 2019, 12, 15-26. [CrossRef]

25. Hu, C.; Qian, A.; Wang, Q.; Xu, F.; He, Y.; Xu, J.; Xia, Y.; Xia, Q. Industrialization of lipid nanoparticles: From laboratory-scale to large-scale production line. Eur. J. Pharm. Biopharm. 2016, 109, 206-213. [CrossRef]

26. Pardeshi, C.; Rajput, P.; Belgamwar, V.; Tekade, A.; Patil, G.; Chaudhary, K.; Sonje, A. Solid lipid based nanocarriers: An overview. Acta Pharm. 2012, 62, 433-472. [CrossRef]

27. Tsuzuki, T. Commercial scale production of inorganic nanoparticles. Int. J. Nanotechnol. 2009, 6, 567-578. [CrossRef]

28. Dhankhar, P. Homogenization fundamentals. IOSR J. Eng. 2014, 4, 8. [CrossRef]

29. Anantaworasakul, P.; Chaiyana, W.; Michniak-Kohn, B.B.; Rungseevijitprapa, W.; Ampasavate, C. Enhanced Transdermal Delivery of Concentrated Capsaicin from Chili Extract-Loaded Lipid Nanoparticles with Reduced Skin Irritation. Pharmaceutics 2020, 12, 463. [CrossRef]

30. Makoni, P.A.; Wa, K.K.; Walker, R.B. Short Term Stability Testing of Efavirenz-Loaded Solid Lipid Nanoparticle (SLN) and Nanostructured Lipid Carrier (NLC) Dispersions. Pharmaceutics 2019, 11, 397. [CrossRef]

31. Naik, J.; Lokhande, A.; Mishra, S.; Kulkarni, R. Development of sustained release micro/nanoparticles using different solvent emulsification technique: A review. Int. J. Pharm. Bio Sci. 2012, 3, 573-590.

32. Kuntsche, J.; Mäder, K. Solid lipid nanoparticles (SLN) for drug delivery. In Handbook of Materials for Nanomedicine; Torchilin, V., Amiji, M.M., Eds.; Pan Stanford Publishing: Singapore, 2010; Volume 1, pp. 383-444.

33. Gall, V.; Runde, M.; Schuchmann, H.P. Extending applications of high-pressure homogenization by using simultaneous emulsification and mixing (SEM) —An overview. Processes 2016, 4, 46. [CrossRef]

34. Severino, P.; Santana, M.H.A.; Souto, E.B. Optimizing SLN and NLC by 22 full factorial design: Effect of homogenization technique. Mater. Sci. Eng. C 2012, 32, 1375-1379. [CrossRef]

35. Zhang, J.; Xu, S.; Li, W. High shear mixers: A review of typical applications and studies on power draw, flow pattern, energy dissipation and transfer properties. Chem. Eng. Process. 2012, 57, 25-41. [CrossRef]

36. López-García, R.; Ganem-Rondero, A. Solid lipid nanoparticles (SLN) and nanostructured lipid carriers (NLC): Occlusive effect and penetration enhancement ability. J. Cosmet. Dermatol. Sci. Appl. 2015, 5, 62-72. [CrossRef]

37. Souto, E.B.; Doktorovova, S.; Zielinska, A.; Silva, A.M. Key production parameters for the development of solid lipid nanoparticles by high shear homogenization. Pharm. Dev. Technol. 2019, 24, 1181-1185. [CrossRef]

38. Maqbool, A.; Mishra, M.K.; Pathak, S.; Kesharwani, A.; Kesharwani, A. Semisolid dosage forms manufacturing: Tools, critical process parameters, strategies, optimization, and recent advances. Ind. Am. J. Pharm. Res. 2017, 7, 882-893.

39. Shimojo, A.A.; Fernandes, A.R.V.; Ferreira, N.R.; Lopez, E.S.; Santana, M.H.A.; Souto, E.B. Evaluation of the Influence of Process Parameters on the Properties of Resveratrol-Loaded NLC Using 22 Full Factorial Design. Antioxidants 2019, 8, 272. [CrossRef]

40. Üner, M. Preparation, characterization and physico-chemical properties of solid lipid nanoparticles (SLN) and nanostructured lipid carriers (NLC): Their benefits as colloidal drug carrier systems. Pharmazie 2006, 61, 375-386.

41. Singh, S.; Singh, M.; Tripathi, C.B.; Arya, M.; Saraf, S.A. Development and evaluation of ultra-small nanostructured lipid carriers: Novel topical delivery system for athlete's foot. Drug Deliv. Transl. Res. 2016, 6, 38-47. [CrossRef]

42. Teeranachaideekul, V.; Müller, R.H.; Junyaprasert, V.B. Encapsulation of ascorbyl palmitate in nanostructured lipid carriers (NLC)—Effects of formulation parameters on physicochemical stability. Int. J. Pharm. 2007, 340, 198-206. [CrossRef] [PubMed]

43. Gardouh, A.R.; Gad, S.; Ghonaim, H.M.; Ghorab, M.M. Design and characterization of glyceryl monostearate solid lipid nanoparticles prepared by high shear homogenization. J. Pharm. Res. Int. 2013, 3, 326-346. [CrossRef]

44. ICH Harmonised Tripartite Guideline. Validation of Analytical Procedures: Text and Methodology, Q2 (R1); ICH Secretariat: Geneva, Switzerland, 2005; pp. 1-15. 
45. Horwitz, W. AOAC Guidelines for Single Laboratory Validation of Chemical Methods for Dietary Supplements and Botanicals; AOAC International: Gaithersburg, MD, USA, 2002; pp. 12-19.

46. Islam, M.T.; Rodriguez-Hornedo, N.; Ciotti, S.; Ackermann, C. Rheological characterization of topical carbomer gels neutralized to different pH. Pharm. Res. 2004, 21, 1192-1199. [CrossRef] [PubMed]

47. Patel, D.K.; Tripathy, S.; Nair, S.K.; Kesharwani, R. Nanostructured lipid carrier (Nlc) a modern approach for topical delivery: A review. World J. Pharm. Pharm. Sci. 2013, 2, 921-938.

48. Kelchen, M.N.; Brogden, N.K. In vitro skin retention and drug permeation through intact and microneedle pretreated skin after application of propranolol loaded microemulsions. Pharm. Res. 2018, 35, 228. [CrossRef]

49. Peng, X.; Zhou, Y.; Han, K.; Qin, L.; Dian, L.; Li, G.; Pan, X.; Wu, C. Characterization of cubosomes as a targeted and sustained transdermal delivery system for capsaicin. Drug Des. Dev. Ther. 2015, 9, 4209-4218. [CrossRef]

50. Trombino, S.; Servidio, C.; Laganà, A.S.; Conforti, F.; Marrelli, M.; Cassano, R. Viscosified Solid Lipidic Nanoparticles Based on Naringenin and Linolenic Acid for the Release of Cyclosporine A on the Skin. Molecules 2020, 25, 3535. [CrossRef]

51. Najafi-Taher, R.; Ghaemi, B.; Amani, A. Delivery of adapalene using a novel topical gel based on tea tree oil nano-emulsion: Permeation, antibacterial and safety assessments. Eur. J. Pharm. Sci. 2018, 120, 142-151. [CrossRef]

52. Bruschi, M.L. Mathematical models of drug release. In Strategies to Modify the Drug Release from Pharmaceutical Systems; Woodhead Publishing: Cambridge, UK, 2015; pp. 63-86.

53. Douglas, K.; Farber, J.; Flynn, S.; Gu, J.; Qin, V.; Shih, J.; Silberg, J.; Wamakima, A.; Cincotta, D.; Tang, J. Zero-Order Controlled Release Kenetics through Polymer Matrices. Available online: https: //pdfs.semanticscholar.org/41f6/0e17d70a31503e22d397095bf4d67758a18d.pdf (accessed on 27 October 2020).

54. Sanderson, M.J.; Smith, I.; Parker, I.; Bootman, M.D. Fluorescence microscopy. Cold Spring Harb. Protoc. 2014, 1042-1065. [CrossRef]

55. Contri, R.V.; Fiel, L.A.; Alnasif, N.; Pohlmann, A.R.; Guterres, S.S.; Korting, M.S. Skin penetration and dermal tolerability of acrylic nanocapsules: Influence of the surface charge and a chitosan gel used as vehicle. Int. J. Pharm. 2016, 507, 12-20. [CrossRef]

56. Stees, M.; Adjei, I.; Labhasetwar, V. A method for quantification of penetration of nanoparticles through skin layers using near-infrared optical imaging. Cosmetics 2015, 2, 225-235. [CrossRef]

57. Neupane, R.; Boddu, S.H.; Renukuntla, J.; Babu, R.J.; Tiwari, A.K. Alternatives to biological skin in permeation studies: Current trends and possibilities. Pharmaceutics 2020, 12, 152. [CrossRef] [PubMed]

58. Rossetti, F.C.; Depieri, L.V.; Bentley, M. Confocal laser scanning microscopy as a tool for the investigation of skin drug delivery systems and diagnosis of skin disorders. In Confocal Laser Microscopy-Principles and Applications in Medicine, Biology, and the Food Sciences; IntechOpen: London, UK, 2013; pp. 99-140. [CrossRef]

59. Morsy, M.A.; Abdel-Latif, R.G.; Nair, A.B.; Venugopala, K.N.; Ahmed, A.F.; Elsewedy, H.S.; Shehata, T.M. Preparation and evaluation of atorvastatin-loaded nanoemulgel on wound-healing efficacy. Pharmaceutics 2019, 11, 609. [CrossRef] [PubMed]

60. Jirova, D.; Liebsch, M.; Basketter, D.; Spiller, E.; Kejlova, K.; Bendova, H.; Marriott, M.; Kandarova, H. Comparison of human skin irritation and photo-irritation patch test data with cellular in vitro assays and animal in vivo data. In Proceedings of the 6th World Congress on Alternatives \& Animal Use in the Lift Sciences, Tokyo, Japan, 21-25 August 2007; pp. 359-365.

Publisher's Note: MDPI stays neutral with regard to jurisdictional claims in published maps and institutional affiliations.

(C) 2020 by the authors. Licensee MDPI, Basel, Switzerland. This article is an open access article distributed under the terms and conditions of the Creative Commons Attribution (CC BY) license (http://creativecommons.org/licenses/by/4.0/). 